\title{
Direct PCR - A rapid method for multiplexed detection of different serotypes of Salmonella in enriched pork meat samples
}

Chin, Wai Hoe; Sun, Yi; Høgberg, Jonas; Than Linh, Quyen; Engelsmann, Pia; Wolff, Anders; Bang, Dang Duong

\section{Published in:}

Molecular and Cellular Probes

Link to article, DOI:

10.1016/j.mcp.2016.11.004

Publication date:

2017

Document Version

Peer reviewed version

Link back to DTU Orbit

Citation $(A P A)$ :

Chin, W. H., Sun, Y., Høgberg, J., Than Linh, Q., Engelsmann, P., Wolff, A., \& Bang, D. D. (2017). Direct PCR A rapid method for multiplexed detection of different serotypes of Salmonella in enriched pork meat samples. Molecular and Cellular Probes, 32, 24-32. https://doi.org/10.1016/j.mcp.2016.11.004

\section{General rights}

Copyright and moral rights for the publications made accessible in the public portal are retained by the authors and/or other copyright owners and it is a condition of accessing publications that users recognise and abide by the legal requirements associated with these rights.

- Users may download and print one copy of any publication from the public portal for the purpose of private study or research.

- You may not further distribute the material or use it for any profit-making activity or commercial gain

- You may freely distribute the URL identifying the publication in the public portal 


\section{Direct PCR - a rapid method for multiplexed detection of different serotypes of Salmonella in enriched pork meat samples}

1 Wai Hoe Chin ${ }^{a}$, Yi Sun ${ }^{\text {b* }}$, Jonas Høgberg ${ }^{c}$, Than Linh Quyen ${ }^{b}$, Pia Engelsmann ${ }^{a}$ Anders Wolff

2 and Dang Duong Bang

$3 \quad{ }^{a}$ National Food Institute, Technical University of Denmark (DTU-Food)

$4 \quad{ }^{b}$ Department of Micro and Nanotechnology, Technical University of Denmark, Denmark (DTU-

$5 \quad$ Nanotech)

$6 \quad$ cNational Veterinary Institute Technical University of Denmark (DTU-Vet)

7 *Corresponding author. Mailing address: Department of Micro and Nanotechnology, Technical

8 University of Denmark, Denmark (DTU-Nanotech)

9 Phone: +45-45256319, E-mail: Sun.Yi@nanotech.dtu.dk

10 Keywords: Direct PCR, Salmonella spp., Rapid detection, Multiplex PCR, Buffered Peptone Water

11 enriched pork meat

\section{Abstract}

13 Salmonellosis, an infectious disease caused by Salmonella spp., is one of the most common

14 foodborne diseases. Isolation and identification of Salmonella by conventional bacterial culture

15 method is time consuming. In response to the demand for rapid on line or at site detection of

16 pathogens, in this study, we developed a multiplex Direct PCR method for rapid detection of

17 different Salmonella serotypes directly from pork meat samples without any DNA purification steps.

18 An inhibitor-resistant Phusion Pfu DNA polymerase was used to overcome PCR inhibition. Four 
19 pairs of primers including a pair of newly designed primers targeting Salmonella spp. at subtype level

20 were incorporated in the multiplex Direct PCR. To maximize the efficiency of the Direct PCR, the

21 ratio between sample and dilution buffer was optimized. The sensitivity and specificity of the

22 multiplex Direct PCR were tested using naturally contaminated pork meat samples for detecting and

23 subtyping of Salmonella spp. Conventional bacterial culture methods were used as reference to

24 evaluate the performance of the multiplex Direct PCR. Relative accuracy, sensitivity and specificity

25 of $98.8 \%$; $97.6 \%$ and $100 \%$, respectively, were achieved by the method. Application of the multiplex

26 Direct PCR to detect Salmonella in pork meat at slaughter reduces the time of detection from 5-6

27 days by conventional bacterial culture and serotyping methods to 14 hours (including 12 hours

28 enrichment time). Furthermore, the method poses a possibility of miniaturization and integration into

29 a point-of-need Lab-on-a-chip system for rapid online pathogen detection.

\section{1. Introduction}

Animal food production plays an important role in the economies of the European Union (EU). In particular, Denmark is one of the top EU countries to export meat. The Danish annual production of pork is around 1,896 million kilograms. Beef and veal production reached a total of 139 million kilograms while poultry production increased up to 191 million kilograms in 2013. In Denmark, the annual budget of exported meat and meat products is estimated around 156 billion Danish krone [1].

36 The increasingly stringent legislation [2] together with heightened public awareness has urged the

37 food industry and the legislation bodies to intensively test animal originated food products to ensure

38 food safety. Salmonella is one of the most common foodborne pathogens found in animal food 39 products. The Salmonella genus is a member of the family Enterobacteriaceae, and has more than

402600 serotypes [3]. In the EU, three Salmonella serovars: Salmonella Enteritidis, Salmonella

41 Typhimurium and Salmonella Infantis are identified as the most frequently found and widely

42 distributed Salmonella serovars in animals used for food production [4]. In Denmark, Salmonella 
43 Typhimurium and Salmonella Derby are identified as the common serotypes associated with pig

44 herds, while Salmonella Enteritidis is associated with layer flocks, and Salmonella Typhimurium and

45 Salmonella Infantis are associated with broiler flocks [5]. Since Salmonella contaminated food

46 products can cause severe infection, a single event of a foodborne disease outbreak can bring

47 unimaginable economic losses. The outbreak not only poses a threat to human health [6], but also

48 severely damages the international reputation of a product or a food company and the potential

49 impact can be devastating [7]. Today, animal food production and distribution networks are

50 becoming quicker and have a greater capacity than ever before. Rapid and multiplex methods suitable

51 for online or at site screening of animal food products are urgently needed in order to expedite the

52 timely release of products for retail distribution as well as to take necessary action to mitigate

53 foodborne diseases outbreak and economic loss.

54 Up to date, conventional bacterial culture methods have been the reference methods for detection 55 of Salmonella in food. The cost of bacterial culture method in Denmark including labour cost was 56 around 50 USD per sample. The methods are expensive and time consuming, requiring up to 5 days

57 to obtain the confirmed results [8]. Apparently, the methods were not fast enough to keep up with the

58 pace of animal food production. In the last decades, several PCR-based methods that include PCR

59 [9], PCR in combination with hybridization [10], immuno-PCR by combining monoclonal antibody

60 coated magnetic bead with PCR [11], PCR in combination with conventional culture and serotyping

61 [12] and real-time PCR [13-18] for rapid detection of Salmonella have been reported. However, all of

62 these methods require a pre-enrichment step of 6-28h followed by tedious DNA isolation and

63 purification procedures to overcome PCR inhibitors. Moreover, most of the methods can only detect

64 certain serovar of Salmonella.

65 In order to reduce the time and complexity of detection, Direct PCR methods have been described 66 in literature. These methods aim to use raw sample as the template for PCR amplification, thus 
67 eliminate the need for DNA purification. The main obstacle in the developing of this Direct PCR is

68 PCR inhibitors. Different strategies have been applied to overcome the effect of the PCR inhibitors

69 such as addition of BSA, protease inhibitors, magnesium ions and chelation of calcium ions.

70 However, the application of such methods depends on the type of inhibitors or specific type of

71 samples [19]. Alternative research focus on re-engineering the thermostable polymerases either by

72 induced point mutations or genetic recombination to enhance processivity and fidelity of the

73 polymerase enzymes. Kermekchiev et al. (2009) reported a N-terminal deletion of mutant Klentaq 1 -

74 variant of Taq DNA polymerase that exhibits 10-100 fold higher inhibition resistant to whole blood

75 in comparison to full-length wild type Taq DNA polymerase which is strongly inhibited by $0.1-1 \%$ of

76 blood. It has been shown that mutations at codon 708 both in the Klentaq 1 and Taq polymerase

77 enhanced resistance to various PCR inhibitors such as whole blood, plasma, hemoglobin, lactoferrin,

78 humic acid and a high concentration of intercalating dyes [20]. Wang et al. [21] reported an

79 engineered Pfu DNA polymerase that has been fusion with a double-strand DNA-binding domain

80 (Sso7d) with high robustness. The enzyme was successfully produced with good processivity, as well

81 as high catalytic activity and enzyme stability [21-22]. In vitro studies have been showed that Sso7d

82 protein can assist in annealing of complementary DNA strands [23] and can causes negative

83 supercoiling [24]. In addition, the fusion of the Sso7d protein domain in a Pfu DNA polymerase

84 showed increase in the tolerance to high salt concentration [21]. The feasibility of this reengineered

85 DNA polymerase has been recently demonstrated by performing Direct PCR on forensic samples

86 [25]. However, this DNA polymerase has seldom been studied or applied for detecting pathogens in

87 food and animal samples at slaughter.

88 In response to the demand for fast at-site detection of pathogens, in this study, we developed a

89 new multiplex Direct PCR to rapidly identify different Salmonella spp, directly from BPW enriched

90 pork meat samples without DNA isolation and purification. This PCR assay can target $S$. 
91 Typhimurium and S. Dublin in natural contaminated samples with accuracy $88.9 \%$ (24 out of 27)

92 and 66.7\% (2 out of 3). The commonly found Salmonella serotype in this study is correlated with the

93 survey report in Denmark [5]. The Direct PCR method possesses high potential for integrating into

94 online detection systems such as Lab-on-a-chip devices, so that animal food industry and regulatory

95 bodies can monitor food quality and food safety at much reduced time and cost.

\section{2. Materials and Methods}

97 2.1. Chemicals

98 All chemicals and reagents used in this study were of analytical grade and purchased from Pierce

99 Inc., USA or Sigma-Aldrich, USA unless otherwise specified.

2.2. Bacterial strains and culture conditions

101

A total of 31 bacterial strains including 15 Salmonella serotypes and 16 non-Salmonella bacterial strains isolated from chickens or pigs were employed to study the sensitivity and the specificity of the

103 Direct PCR (Table 1). All of the strains were provided by National Food Institute (DTU-Food). They

104 were originated from the Culture Collection at University of Gothenburg (CCUG) Sweden, the 105 National Collection of Type Culture (NCTC) or the Veterinary Diagnostic Laboratory (VDL) UK.

106 The Salmonella strains were resuscitated and grown on 5\% Blood agar (BA) plates (Statens Serum

107 Institute, Copenhagen, Denmark). A standard culture method (ISO 6579:2002/ Amd.1:2007(E)) with

108 some modifications according to recommendations from Nordic Committee on Food Analyses

109 (NMKL) was used [26] for detection of Salmonella. The optimum 8 hours incubation time of

110 samples in BPW already described [16], however in this studied we used 12 hours of incubation.

111 The method was carried out to confirm the presence of Salmonella in natural contaminated pork meat

112 samples at the slaughter. Briefly, the pork meat samples were collected at slaughter and enriched 
$113(1: 10 \mathrm{w} / \mathrm{v})$ in pre-warmed Buffered Peptone Water (BPW, Merck, Darmstadt, Germany) for $12 \pm 2 \mathrm{~h}$

114 at $37{ }^{\circ} \mathrm{C}$. Three drops $(\sim 100 \mu \mathrm{l})$ of the enriched BPW sample were transferred onto Modified

115 Semisolid Rappaport-Vassiliadis (MSRV) plates and further incubated for another $24 \mathrm{~h}$ at $41.5{ }^{\circ} \mathrm{C}$.

116 Suspected colonies were streaked onto the selective plating media Xylose Lysine Deoxycholate

117 (XLD) (Oxoid, United Kingdom) and Rambach agar (Merck). The plates were incubated at $37^{\circ} \mathrm{C}$ for

118 24h, and the suspected Salmonella-positive colonies were transferred to BA plates and confirmed by

119 API 20E (bioMérieux, Marcy l’Étoile, France) and serotyping [27].

120 Campylobacter strains were resuscitated and selected on Charcoal Cefoperazone Deoxycholate 121 Agar (CCDA) (Oxoid) and grown on BA at $42{ }^{\circ} \mathrm{C}$ in microaerophilic conditions (6\% $\mathrm{O}_{2}, 6 \% \mathrm{CO}_{2}$,

122 and 88\% $\mathrm{N}_{2}$ ) before use. Other bacterial strains including Escherichia coli (E.coli), Streptococcus

123 pneumonia, Enterococcus faecalis, Enterococcus faecium, Proteus hauseri, Citrobacter freundii,

124 Yersinia ruckeri were grown on BA places and incubated at $37^{\circ} \mathrm{C}$, while Arcobacter cryaerophilus, 125 Arcobacter butzleri and Arcobacter skirrowii strains were incubated at $15{ }^{\circ} \mathrm{C}$ or room temperature.

126 2.3. DNA preparation

127 To test the specificity and sensitivity of the method, chromosomal DNA from different bacterial 128 strains (Table 1) was isolated using DNeasy Blood and Tissue kit (Qiagen, Germany). The 129 concentration of the DNA was determined by Nano drop (Thermo Scientific, USA). Two ng/pl of the 130 chromosomal DNA were used to test the performance of the Direct PCR.

131 2.4. Primers for the Direct PCR

132 Specific PCR primers for amplification of different Salmonella serotypes were either selected

133 from literature or designed based on multiple alignments of Salmonella and non-Salmonella 134 sequences of individual genes using Primer-BLAST from NCBI 135 (http://www.ncbi.nlm.nih.gov/tools/primer-blast/). The specificity of hilA gene (GenBank U25352) 
136 from Salmonella spp. was checked by NCBI BLAST (https://blast.ncbi.nlm.nih.gov/Blast.cgi) with

137 the highly similar sequences (megablast) program selection. It was showed that it is only unique to

138 and ubiquitous in Salmonella enterica. The primers targeting hilA gene were designed on the basis of

139 an alignment to Salmonella enterica (GenBank U25352). The primers were selected and compared

140 with all nucleotide collection (nr/nt) organism database available in NCBI BLAST with $100 \%$ query

141 cover and $\mathrm{E}$ value of 0.02 for forward primer and $\mathrm{E}$ value of $5 \times 10^{-4}$ for reverse primer. The

142 sequences are shown in Table 2. The primers were synthesized by DNA Technology (Aarhus,

143 Denmark).2.5. Optimization of sample dilution condition for the Direct PCR

144 In order to evaluate the effect of sample dilution on the efficiency of Direct PCR, $2 \mu l$ of pork

145 meat sample enriched in BPW was spiked with Salmonella cells and then diluted in PBS buffer at

146 different ratios of $1: 1,1: 3,1: 8,1: 10$, and $1: 100$. Two $\mu$ l of each dilution were used as the template in

147 the Direct PCR reaction. The optimized sample dilution ratio was applied for the rest of the Direct 148 PCR experiments.

\section{2.6. Direct multiplex PCR assay}

150 The Direct PCR was performed with $2 \mu$ of the diluted pork meat sample (1: 10 dilution in PBS)

151 in $10 \mu \mathrm{l}$ of the Direct PCR mixture containing $200 \mathrm{nM}$ of hilA primer, $300 \mathrm{nM}$ of fliC primer, 100

$152 \mathrm{nM}$ of $s d f$ primer, and $100 \mathrm{nM}$ of sefA primer; 1 x Phusion ${ }^{\circledR}$ Human Specimen PCR Buffer and 0.04

$153 \mathrm{U} / \mu \mathrm{l}$ Phusion Human Specimen DNA Polymerase (Thermo Fisher Scientific, USA). The PCR was

154 conducted in PikoReal ${ }^{\mathrm{TM}}$ Real-Time PCR System (Thermo Fisher Scientific, USA). The PCR

155 conditions were $98{ }^{\circ} \mathrm{C}$ for 2 minutes following by 38 cycles of $98{ }^{\circ} \mathrm{C}$ for 15 seconds, $60{ }^{\circ} \mathrm{C}$ for 15

156 seconds and $72{ }^{\circ} \mathrm{C}$ for 1 minute. PCR amplification was confirmed by $2 \%$ agarose gels

157 electrophoresis containing SYBR® Safe DNA Gel Stain (Invitrogen, Life Technologies, USA).

158 2.7. Sensitivity of the Direct PCR 
159 To test the sensitivity of the Direct PCR, two different approaches were selected:

160 a) Salmonella DNA-spiked samples:

161 The 10-fold serial dilutions of pure DNA from S. Enteritidis and S. Typhimurium were spiked in 162 pork meat samples enriched in BPW, giving final concentration ranging from $0.01 \mathrm{pg} / \mu \mathrm{l}$ to $10 \mathrm{ng} / \mu \mathrm{l}$.

163 b) Salmonella cell-spiked samples:

164 The 10-fold serial dilutions of Salmonella cells were prepared from S. Enteritidis (CCUG 32352)

165 and S. Typhimurium (Jeo 3979 Jgt.110) stocks ( $\mathrm{OD}_{600}=0.8$, corresponding to $10^{8}$ cells $/ \mathrm{ml}$ ). The 166 Salmonella cells were spiked in pork meat samples enriched in BPW to give final concentrations 167 ranging from $10^{0}$ to $10^{7} \mathrm{CFU} / \mathrm{ml}$. A non-spiked sample was included as a negative control.

168 2.8. Comparison of sensitivity of Direct PCR and conventional PCR used at slaughter

169 The sensitivity of the Direct PCR was compared to the conventional PCR used at slaughter in 170 which Tth DNA polymerase was employed. The main purpose for this experiment was to compare 171 the sensitivity of direct PCR and conventional PCR used at slaughter without pre-sample preparation.

172 Both experiments employed the same primers set developed in this study to eliminate the discrepancy

173 from primers. The conventional PCR used at slaughter PCR mixture contained 0.06 U/ $\mu$ of Tth DNA 174 polymerase (Roche Applied Science, Mannheim, Germany), 1× of PCR buffer (Roche Applied 175 Science, Mannheim, Germany), $200 \mathrm{nM}$ of hilA primer, $300 \mathrm{nM}$ of fliC primer, $100 \mathrm{nM}$ of sdf 176 primer, and $100 \mathrm{nM}$ of sefA primer, $500 \mu \mathrm{M}$ deoxynucleoside triphosphate with dUTP (Applied 177 Biosystems, Foster city, CA), 8\% glycerol (Merck, Darmstadt, Germany), 4.0 mM MgCl 2 (Roche 178 Applied Science), 2\% dimethyl sulfoxide (Sigma, Steinheim, Germany), and $1 \mathrm{~g} /$ liter bovine serum 179 albumin (Roche Applied Science). The PCR conditions were $95^{\circ} \mathrm{C}$ for $3 \mathrm{~min}$, followed by 40 cycles 180 of $95{ }^{\circ} \mathrm{C}$ for 30 seconds, $60{ }^{\circ} \mathrm{C}$ for 60 seconds, and $72{ }^{\circ} \mathrm{C}$ for 30 seconds. The PCR reaction was 181 performed using a thermocycler (T3 Thermocycle Biometra, Göttingen, Germany). The PCR 
182 amplicon was detected on $2 \%$ agarose gels electrophoresis containing SYBR® Safe DNA Gel Stain

183 (Invitrogen, Life Technologies, USA). The conventional PCR used at slaughter was performed in

184 conventional thermo cycler instead of the PikoReal PCR system because PCR reaction with the Tth

185 DNA polymerase using the PikoReal PCR system always gave negative results (data not shown). The

186 reason might be the processivity of Tth DNA polymerase is not compatible with the fast ramp rate in

187 PikoReal ${ }^{\mathrm{TM}}$ PCR System. Therefore, the conventional PCR used at slaughter was performed in

188 conventional thermos cycler model to get the highest efficiency.

189 2.9. Evaluation of the developed Direct PCR method using naturally contaminated pork meat 190 samples enriched in BPW at slaughter

191 A total number of 82 pork meat samples (25g for each) were collected at slaughter and enriched in 192225 ml Buffered Peptone Water ( BPW) (Danish Crown, Herning, Denmark). The samples were 193 transferred to the laboratory in 250 ml Dispatch Container Nunc (Life Technologies, Nærum, 194 Denmark). On arrival, the sample were subjected immediately to laboratory processing or stored at $1955^{\circ} \mathrm{C}$ before testing. All the samples were tested for Salmonella by the modified conventional bacterial 196 culture (ISO 6579), TaqMan real-time PCR [26] and the multiplex Direct PCR assays.

A comparative trial between the multiplex Direct PCR and the conventional bacterial culture 199 (ISO 6579) was designed and conducted according to the MICROVAL protocol [28], relative 200 sensitivity, specificity and accuracy were calculated according to the following formulas:

201

202

1) Relative accuracy: $\mathrm{AC}=\frac{(P A+N A)}{N} \times 100 \%$

2) Relative specificity: SP $=\frac{N A}{N-} \times 100 \%$

203

3) Relative sensitivity: $\mathrm{SE}=\frac{P A}{N+} \times 100 \%$ 
204 where:

205 PA is the positive agreement between the culture and the Direct PCR methods;

206 NA is the negative agreement between the culture and the Direct PCR methods;

207 PD is the false positives of the Direct PCR method;

208 ND is the false negatives of the Direct PCR method;

$209 \mathrm{~N}$ is the total number of samples (NA+PA+PD+ND);

$210 \mathrm{~N}$ - is the total number of negative results with the reference method (NA+PD) and

$211 \mathrm{~N}+$ is the total number of positive results with the reference method (PA+ND)

212 Cohen's kappa statistic was performed to assess the agreement between direct PCR, conventional

213 culture method and conventional PCR used at slaughter. The values of 0.00 to 0.20 indicate poor

214 agreement, 0.21 to 0.40 indicate fair agreement, 0.41 to 0.60 indicate moderate agreement, 0.61 to

2150.80 indicate good agreement, and 0.81 to 1.00 indicate excellent agreement.

216 3. Results and discussion

217 3.1. Development of multiplex Direct PCR for Salmonella detection

218 3.1.1. Selectivity of target gene primers

219 Previously, a real-time multiplex PCR method has been developed to detect Salmonella and 220 differentiate different Salmonella serotypes (S. Typhimurium, S. Enteritidis, S. Dublin, S.

221 Gallinarum, S. Kentucky) in chicken meat [29]. Four primer pairs targeting fliC gene, sdf gene, sefA 222 gene and aceK gene have been described (Table 2). In this study, initial experiments were carried out 223 to test the specificity of the four primer pairs for differentiating Salmonella and non-Salmonella 224 reference strains in pork meat samples. A total of 31 bacterial strains including 15 Salmonella 
serotypes and 16 non-Salmonella bacterial strains were tested (Table 1). The experiments revealed

226 that the fliC gene primers were able to detect $S$. Typhimurium specifically, the sdf gene primers were

227 specific to $S$. Enteritidis and the sefA gene primers were specific for $S$. Enteritidis, $S$. Dublin and $S$.

228 Paratyphi A serotypes. The results were in agreement with the results described previously [29]. The

229 fliC gene targets i-antigen specific phase 1 flagellin which is also expressed in uncommon serotypes

230 such as Aberdeen, Bergen and Kedougou [29]. It was showed that fliC gene is positive in real time

231 PCR for 17 samples of S. Typhimurium and negative for 45 non-Typhimurium (both Salmonella and

232 non-Salmonella) samples [30]. The sdf gene was also shown to be able to clearly distinguish S.

233 Enteritidis from 73 non-S. Enteritidis isolates including 34 different serovars such as Dublin and

234 Pullorum that are very close relative to Enteritidis [31]. In another study, by using PCR targeting

235 sefA gene, S. Enteritidis and S. Senftenberg strains could be identified from a total of 101 strains of

236 bacteria consisting of 14 Salmonella spp. and 10 non-Salmonella serovars. [32]. This showed that

237 fliC, sdf and sefA genes can be used for detection of Salmonella with different serotypes. The fliC, sdf

238 and sefA genes are single copy gene and are located on the chromosome.

239 However, when we used the aceK gene primers to detect Salmonella genus in pork meat samples

240 enriched in BPW, there were a number of false positive PCR (data not shown). The aceK gene have

241 previously been shown to be specific for detecting Salmonella spp. in chicken samples [29], but this

242 was not the case for the enriched pork meat samples. This discrepancy could be explained by the fact

243 that the microflora and fauna in pork is different from poultry, therefore primers targeting aceK gene

244 might falsely identify other species than Salmonella spp. in pork meat samples enriched in BPW.

245 Therefore a new primer pair targeting Salmonella spp. for the multiplex Direct PCR is needed. The

246 hilA gene of Salmonella is known to be responsible for the regulation of the Type III secretion

247 system (T3SS) [33], in cell invasion and in causing systemic infection. It is located in pathogenicity

248 island (SPI-1) and real-time PCR targeting hilA gene can differentiate 57 different Salmonella strains 
and 30 non-Salmonella strains [17]. The gene has been shown to be a potential candidate for PCR

250 reaction in research, clinical diagnostic and industrial for the detection of Salmonella enterica

251 subspecies Enterica [10]. Based on the hilA sequence data from Genbank (U25352), we designed a

252 new hilA primer pair targeting Salmonella genus. The new hilA gene primers targets a 225 bp-

253 region starting from the position 1241 bp of the hilA gene. The new hilA gene primer pair was used

254 together with the other three primer pairs (sefA, sdf and fliC) in the developed Direct PCR (Table 2).

255 The multiplex Direct PCR was able to identify and differentiate 15 different Salmonella serotypes 256 from 16 non-Salmonella bacteria strains (Table 1).

257 3.1.2. Optimization of sample dilution condition for the Direct PCR.

258 In this study, the robustness of the Pfu DNA polymerase was evaluated using raw pork meat 259 samples enriched in BPW. The enriched meat sample is a complex food matrix which contains high 260 background of normal microbiota and microflora [34] as well as a high concentration of PCR 261 inhibitors. Monteiro et al. [35] reported a simple strategy to reduce the effects of PCR inhibitors by 262 diluting the sample. Hence, the pork meat samples were diluted in PBS buffer at different ratios (1:1, 263 1:3, 1:8, 1:10, and 1:100) in order to optimize the condition for the Direct PCR (Table 3).

264 The effect of dilution ratio on the efficiency of Direct PCR is shown in Fig 1 . When $2 \mu$ l of the 265 raw and 1:1 diluted pork meat samples enriched in BPW were used as template for the Direct PCR, 266 no PCR inhibition effect was observed in most of the cases. However, PCR results were inconsistent 267 when performing the multiplex Direct PCR with samples that contain Salmonella serotype 4,5,12:i:268 (Jeo 297 Jgt.110) and S. Dublin (H 64004) (Table 3). High concentration of potential PCR inhibitors 269 from the sample might be the cause of this inconsistency, since more reproducible results were 270 observed after dilution of 1:3 (Table 3). The highest PCR efficiency was achieved at the dilution 
271 1:10, whereas the amplification efficiency decreased with further dilutions (1:100). Hence the

272 dilution ratio of 1:10 was used for the multiplex Direct PCR in the following experiments.

273 3.2. Detection limit of the Direct PCR

274 To determine the sensitivity of the multiplex Direct PCR, two different approaches were used: 1)

275 the use of DNA-spiked pork meat samples enriched in BPW; and 2) the use of Salmonella cell-spiked 276 pork meat samples enriched in BPW. Fig 2 and Fig 3 show the results of such experiments in gel

277 electrophoresis. The limit of detection (LOD) of the multiplex Direct PCR using the DNA spiked

278 samples was 100 pg DNA for both $S$. Enteritidis and $S$. Typhimurium (Fig. 2a and 2e). For the

279 bacterial cell spiked samples, the LOD of the Direct PCR method for both $S$. Enteritidis and S.

280 Typhimurium was $\sim 10^{5} \mathrm{CFU} / \mathrm{ml}$ (Fig. 3a and 3e).

281 The Direct PCR was compared to the conventional PCR used at slaughter in terms of sensitivity.

282 In the conventional PCR at slaughter, Tth DNA polymerase from thermophilic eubacterium Thermus

283 thermophilus HB8 was used. The Tth DNA polymerase showed better performance than other DNA

284 polymerase such as Taq DNA polymerase [36]. In this study, the sensitivity of both the conventional

285 PCR at slaughter and the Direct PCR were tested using Salmonella pure DNA (Fig 2 a, c, e and g)

286 and DNA spiked pork meat sample enriched in BPW (Fig 2 b, d, f, and h). The LOD of the Direct

287 PCR using Salmonella pure DNA (without any PCR inhibitor) was determined as low as 1 pg DNA

288 for both S. Enteritidis (Fig. 2a) and S. Typhimurium (Fig. 2e); while for the conventional PCR at

289 slaughter, the LOD was determined to be $100 \mathrm{pg}$ for both $S$. Enteritidis (Fig. 2c) and $S$.

290 Typhimurium (Fig. 2g). When DNA-spiked pork meat samples were used as templates, the LOD of

291 the Direct PCR was 10 pg for S. Enteritidis (Fig. 2b) and 100 pg for S. Typhimurium (Fig. 2f),

292 whereas no PCR amplification was observed for either S. Enteritidis (Fig. 2d) or S. Typhimurium

293 (Fig. 2h) in the conventional PCR at slaughter. In summary, the LOD of the Direct PCR was 100 
folds lower than that of the conventional PCR at slaughter when using pure DNA. In contrast, when testing the two methods with the DNA spiked BPW samples, the LOD of the Direct PCR was 1,00010,000 time lower than that of the conventional PCR at slaughter.

The sensitivity of the Direct PCR and the conventional PCR at slaughter were also tested using pure Salmonella cells (Fig 3 a, c, e, and g) and Salmonella cell- spiked enriched pork meat samples (Fig $3 \mathrm{~b}, \mathrm{~d}, \mathrm{f}$, and h). The LOD of the Direct PCR was determined to be as low as $10^{2} \mathrm{CFU} / \mathrm{ml}$ for both S. Enteritidis cells (Fig. 3a) and S. Typhimurium (Fig. 3e), while for the conventional PCR at slaughter the LOD was $\sim 10^{6} \mathrm{CFU} / \mathrm{ml}$ for $S$. Enteritidis (Fig. 3c) and $\sim 10^{5} \mathrm{CFU} / \mathrm{ml}$ for $S$. Typhimurium (Fig. 3g), respectively. In contrast, when using spiked meat samples, no PCR amplification was observed for both Salmonella serotype (Fig. 3d and h) in the conventional PCR at slaughter, while with the Direct PCR, a LOD of $10^{4} \mathrm{CFU} / \mathrm{ml}$ were archived (Fig. $3 \mathrm{~b}$ and $\mathrm{f}$ ).

Therefore, the LOD of the Direct PCR is 1,000 - 10,000 times lower than that of the conventional 306 PCR at slaughter, suggesting that the Pfu DNA polymerase has higher amplification efficiency than Tth DNA polymerase. Moreover, a shorter total reaction time of 43 minutes was archived for the Direct PCR in comparison to 138 minutes reaction time of the conventional PCR at slaughter. The shorter reaction time of the Direct PCR was attributed to the high processivity of the Pfu DNA polymerase that allowed faster amplification as well as removal of the extension step of PCR reaction.

314 polymerase, such as the higher tolerant to PCR inhibitors, the ability to omit the sample purification 315 step, faster amplification and the short reaction time, make the Direct PCR a suitable method for 316 online or at site Salmonella screening at food production industry. The legislative demand of 317 Salmonella detection is 1 CFU/25g sample. In case 1 Salmonella cell present in the sample (25g), 
318 according to Zheng et al. [37], after 12-hr of enrichment in BPW buffer, the average number of

319 Salmonella will reach around $10^{6}-10^{7} \mathrm{CFU} / \mathrm{ml}$. With this range of bacterial concentration, the LOD

320 of $\sim 10^{4} \mathrm{CFU} / \mathrm{ml}$ of the developed multiplex Direct PCR method is more than sufficient to meet the

321 legislative requirements.

322 3.3. Evaluation of Direct PCR using naturally contaminated pork samples

323 The developed multiplex Direct PCR was used for on-field testing of the pork meat samples at

324 slaughter. A total of 82 pork meat samples enriched in BPW at slaughter were collected and tested

325 using the multiplex Direct PCR. Of these 82 samples, 40 were positive for Salmonella spp. and 42

326 were negative for Salmonella (Table 4). Among the 40 Salmonella positive samples, 24 were positive

327 for both hilA and fliC and were defined as S. Typhimurium; while 14 samples were positive for hilA

328 genes and were determined as Salmonella spp., and 2 other samples positive for both hilA and sefA

329 genes were determined as $S$. Dublin. These 82 samples were also tested using standard bacterial

330 culture (ISO6579) combined with Salmonella serotyping. The results showed 41 samples were

331 positive and 41 were negative for Salmonella. Among the 41 Salmonella positive sample, the

332 serotyping revealed that 27 were identified as $S$. Typhimurium, 11 were Derby and 3 were $S$. Dublin.

333 In total, 78 out of the 82 samples identified by the Direct PCR method agreed well with the

334 standard bacterial culture (ISO 6579) on the presence of Salmonella as well as the corresponding

335 serotyping. In addition, for the 11 isolates that were identified as $S$. Derby by bacterial culture in

336 combination with serotyping, all were positive for hilA gene using the Direct PCR and were thus

337 identified as Salmonella spp. For further evaluation, it is important to include target gene that is able

338 to identify S. Derby. Four samples showed discrepancy between the two methods. Three samples

339 were identified as $S$. Typhimurium according to the bacterial culture and serotyping, whereas they

340 were identified as Salmonella spp. by the multiplex Direct PCR since positive PCRs were only 
341 observed for the hilA gene primers (Table 4). Therefore, 14 samples identified as “other Salmonella

342 spp.” by the Direct PCR actually consisted of 11 S. Derby samples and 3 S. Typhimurium samples.

343 One sample was identified as $S$. Dublin by bacterial culture, but negative for the sefA gene by the

344 multiplex Direct PCR. Using the formulas described in Section 2.10, relative accuracy, sensitivity

345 and specificity of 98.8\%; 97.6\% and 100\%, respectively, were achieved for the multiplex Direct PCR

346 (Table 5). The Cohen’s kappa test showed excellent agreement between direct PCR, conventional

347 culture method and TaqMan real-time PCR (Cohen's kappa $=0.81$ ). The cost of single direct PCR is

348 around 0.9 USD (only cost of buffer), therefore it can be another alternative for the industry. Lastly,

349 we suggest including an internal amplification control (IAC) in PCR reaction for future evaluation in

350 the industry. However, the influence of IAC should take into consideration since it may compete with

351 target genes.

\section{4. Conclusion}

In this study, by combining two strategies - the use of the Pfu DNA polymerase and sample

354 dilution, we developed a new multiplex Direct PCR for rapid and multiplex detection of different

355 Salmonella serotypes directly from BPW enriched pork meat samples without DNA isolation and

356 purification steps. The Phusion Pfu DNA polymerase showed high resistance to PCR inhibitors in

357 food matrix. The method enabled rapid detection and differentiation of different Salmonella

358 serotypes in one reaction within 43 minutes (PCR reaction time only) or 14 hours when including

359 12h of enrichment time. The new multiplex Direct PCR was used to detect Salmonella at sub-species

360 directly from 82 pork meat samples enriched in BPW at slaughter and compared to conventional

361 bacterial culture in combination with serotyping. Relative accuracy of $98.8 \%$ with a sensitivity of

362 97.6\% and specificity of 100\%, were achieved. The Direct PCR method possesses potential to be

363 used by the food industry and regulatory bodies to monitor food quality and security with much

364 reduced time and cost. Moreover, owing to the rapid and easy manipulation, the developed Direct 
PCR is ideally suitable for miniaturization and integration into a Lab-on-a-chip system for online 366 foodborne pathogen detection [38-39].

\section{Conflict of interest}

368 The authors declare that there is no conflict of interest.

\section{Acknowledgement}

This work is co-supported by The Danish Innovationsfonden - the HTF SMARTDETECT funded project, Grant No. 118-2012-3.

We thank Professor Dr. Karl Pedersen and Dr Vinayaka Aaydha Chidambara for pre-review this manuscript, and Mrs. Kirsten Kirkeby from Danish Crown Herming, Denmark for providing the BPW enrichment pork meat samples.

375

376

377

378

379

380

381

382

383

384

385

386

387

388

389

390

391

\section{References}

[1] Anonymous, Facts and figures about Danish agriculture and food 2014, (2014). http://www.agricultureandfood.dk/ /media/lf/Tal og analyser/Aarsstatistikker/Fakta om Erhvervet/2014/Facts and Figures/Facts and figures 2015.ashx.

[2] T. Chillaud, The World Trade Organisation Agreement on the Application of Sanitary and Phytosanitary Measures, Rev. Sci. Tech. L Off. Int. Des Epizoot. 15 (1996) 733-741.

[3] O. Gal-Mor, E.C. Boyle, G.A. Grassl, Same species, different diseases: how and why typhoidal and non-typhoidal Salmonella enterica serovars differ, Front. Microbiol. 5 (2014). doi:10.3389/fmicb.2014.00391.

[4] EFSA, The Community Summary Report on trends and sources of zoonoses, zoonotic agents and food-borne outbreaks in the European Union in 2008., EFSA J. 8 (2010).

[5] Anonymous, Annual Report on Zoonoses in Denmark 2009 - DTU Findit, (2010). http://findit.dtu.dk/en/catalog/2185763167 (accessed December 9, 2014).

[6] Centers for Disease Control and Prevention, Vital Signs: Incidence and Trends of Infection with Pathogens Transmitted Commonly Through Food -- Foodborne Diseases Active Surveillance Network, 10 U.S. Sites, 1996-2010., MMWR Morb. Mortal. Wkly. Rep. 60 (2011). 
392

393

394

395

396

397

398

399

400

401

402

403

404

405

406

407

408

409

410

411

412

413

414

415

416

417

418

419

420

421

422

423

424

425

426

427

[7] M. Hussain, C. Dawson, Economic Impact of Food Safety Outbreaks on Food Businesses, Foods. 2 (2013) 585-589. doi:10.3390/foods2040585.

[8] Anonymous, Microbiology of food and animal feeding stuffs. Horizontal method for the detection of Salmonella spp. ISO 6579:2002. German version EN ISO 6579:2002., Ger. Stand. (2002).

[9] S. Makino, H. Kurazono, M. Chongsanguam, H. Hayashi, H. Cheun, S. Suzuki, T. Shirahata, Establishment of the PCR system specific to Salmonella spp. and its application for the inspection of food and fecal samples., J. Vet. Med. Sci. 61 (1999) 1245-1247. doi:10.1292/jvms.61.1245.

[10] N. Cardona-Castro, E. Restrepo-Pineda, M. Correa-Ochoa, Detection of hilA gene sequences in serovars of Salmonella enterica subspecies enterica, Mem. Inst. Oswaldo Cruz. (2002). doi:10.1590/S0074-02762002000800016.

[11] A.N. Moreira, F.R. Conceição, R.D.C.S. Conceição, R.J. Ramos, J.B. Carvalhal, O. a Dellagostin, J. a G. Aleixo, Detection of Salmonella typhimurium in raw meats using in-house prepared monoclonal antibody coated magnetic beads and PCR assay of the fimA gene., J. Immunoassay Immunochem. 29 (2008) 58-69. doi:10.1080/15321810701735096.

[12] M.M. Gwida, M.A.M. Al-Ashmawy, Culture versus PCR for Salmonella Species Identification in Some Dairy Products and Dairy Handlers with Special Concern to Its Zoonotic Importance., Vet. Med. Int. 2014 (2014) 502370. doi:10.1155/2014/502370.

[13] J.L.E. Ellingson, J.L. Anderson, S. a. Carlson, V.K. Sharma, Twelve hour real-time PCR technique for the sensitive and specific detection of Salmonella in raw and ready-to-eat meat products, Mol. Cell. Probes. 18 (2004) 51-57. doi:10.1016/j.mcp.2003.09.007.

[14] H.-M. Nam, V. Srinivasan, B.E. Gillespie, S.E. Murinda, S.P. Oliver, Application of SYBR green real-time PCR assay for specific detection of Salmonella spp. in dairy farm environmental samples., Int. J. Food Microbiol. 102 (2005) 161-171. doi:10.1016/j.ijfoodmicro.2004.12.020.

[15] B. Malorny, E. Paccassoni, P. Fach, C. Bunge, A. Martin, R. Helmuth, Diagnostic real-time PCR for detection of Salmonella in food, Appl. Environ. Microbiol. 70 (2004) 7046-7052. doi:10.1128/AEM.70.12.7046-7052.2004.

[16] M.H. Josefsen, M. Krause, F. Hansen, J. Hoorfar, Optimization of a 12-hour TaqMan PCRbased method for detection of Salmonella bacteria in meat, Appl. Environ. Microbiol. 73 (2007) 3040-3048. doi:10.1128/AEM.02823-06.

[17] E.M. McCabe, C.M. Burgess, E. O’Regan, S. McGuinness, T. Barry, S. Fanning, G. Duffy, Development and evaluation of DNA and RNA real-time assays for food analysis using the hilA gene of Salmonella enterica subspecies enterica, Food Microbiol. 28 (2011) 447-456. doi:10.1016/j.fm.2010.10.012. 
[18] J. Cao, L. Xu, M. Yuan, B. Ke, D. Xiang, TaqMan Probe Real-time PCR Detection of Foodborne Salmonella enterica and Its Six Serovars, 2 (2013) 1-12.

[19] C. Schrader, a. Schielke, L. Ellerbroek, R. Johne, PCR inhibitors - occurrence, properties and removal, J. Appl. Microbiol. 113 (2012) 1014-1026. doi:10.1111/j.1365-2672.2012.05384.x.

[20] M.B. Kermekchiev, Mutants of Taq DNA polymerase resistant to PCR inhibitors allow DNA amplification from whole blood and crude soil samples., Nucleic Acids Res. 37 (2009) e40. doi:10.1093/nar/gkn1055.

[21] Y. Wang, D.E. Prosen, L. Mei, J.C. Sullivan, M. Finney, P.B. Vander Horn, A novel strategy to engineer DNA polymerases for enhanced processivity and improved performance in vitro, Nucleic Acids Res. 32 (2004) 1197-1207. doi:10.1093/nar/gkh271.

[22] P. Yang, Efficient PCR from whole blood using finnzymes high performance PCR solution, Nat. Methods. (2007) 20-21.

[23] a. Guagliardi, L. Cerchia, M. Rossi, Prevention of in vitro protein thermal aggregation by the Sulfolobus solfataricus chaperonin. Evidence for nonequivalent binding surfaces on the chaperonin molecule, J. Biol. Chem. 270 (1995) 28126-28132. doi:10.1074/jbc.270.47.28126.

[24] P. López-García, S. Knapp, R. Ladenstein, P. Forterre, In vitro DNA binding of the archaeal protein Sso7d induces negative supercoiling at temperatures typical for thermophilic growth, Nucleic Acids Res. 26 (1998) 2322-2328. doi:10.1093/nar/26.10.2322.

[25] S. Verheij, J. Harteveld, T. Sijen, A protocol for direct and rapid multiplex PCR amplification on forensically relevant samples, Forensic Sci. Int. Genet. 6 (2012) 167-175. doi:10.1016/j.fsigen.2011.03.014.

[26] C. Löfström, F. Hansen, S. Mansdal, J. Hoorfar, Detection of Salmonella in meat: comparative and interlaboratory validation of a noncomplex and cost-effective pre-PCR protocol., J. AOAC Int. 95 (2012) 100-4. http://www.ncbi.nlm.nih.gov/pubmed/22468347 (accessed March 18, 2015).

[27] P. Grimont, F.-X. Weill, Antigenic formulae of the Salmonella servovars, WHO Collab. Cent. Ref. Res. Salmonella. 1-167. http://www.pasteur.fr/ip/portal/action/WebdriveActionEvent/oid/01s-000036089\npapers2://publication/uuid/CA3447A0-61BF-4D62-9181-C9BA78AF0312.

[28] Anonymous, Microbiology of food and animal feeding stuffs. Protocol for the validation of alternative methods. ISO 16140:2003., (2003).

[29] E. O’Regan, E. McCabe, C. Burgess, S. McGuinness, T. Barry, G. Duffy, P. Whyte, S. Fanning, Development of a real-time multiplex PCR assay for the detection of multiple Salmonella serotypes in chicken samples., BMC Microbiol. 8 (2008) 156. doi:10.1186/14712180-8-156.

[30] A. V Hadjinicolaou, V.L. Demetriou, M.A. Emmanuel, C.K. Kakoyiannis, L.G. Kostrikis, 
Molecular beacon-based real-time PCR detection of primary isolates of Salmonella Typhimurium and Salmonella Enteritidis in environmental and clinical samples, BMC Microbiol. 9 (2009) 97. doi:10.1186/1471-2180-9-97.

[31] P.G. Agron, Identification by Subtractive Hybridization of Sequences Specific for Salmonella enterica Serovar Enteritidis, Appl. Environ. Microbiol. 67 (2001).

[32] C. Soumet, G. Ermel, V. Rose, N. Rose, P. Drouin, G. Salvat, P. Colin, Identification by a multiplex PCR-based assay of Salmonella Typhimurium and Salmonella Enteritidis strains from environmental swabs of poultry houses, Lett. Appl. Microbiol. 29 (1999) 1-6. doi:10.1046/j.1365-2672.1999.00559.x.

[33] M.L. Lesnick, N.E. Reiner, J. Fierer, D.G. Guiney, The Salmonella spvB virulence gene encodes an enzyme that ADP-ribosylates actin and destabilizes the cytoskeleton of eukaryotic cells, Mol. Microbiol. 39 (2001) 1464-1470. doi:10.1046/j.1365-2958.2001.02360.x.

[34] D.M. Prendergast, S.J. Duggan, U. Gonzales-Barron, S. Fanning, F. Butler, M. Cormican, G. Duffy, Prevalence, numbers and characteristics of Salmonella spp. on Irish retail pork, Int. J. Food Microbiol. 131 (2009) 233-239. doi:10.1016/j.ijfoodmicro.2009.03.003.

[35] L. Monteiro, D. Bonnemaison, A. Vekris, K.G. Petry, J. Bonnet, R. Vidal, J. Cabrita, F. Mégraud, Complex polysaccharides as PCR inhibitors in feces: Helicobacter pylori model, J. Clin. Microbiol. 35 (1997) 995-998.

[36] S.K. Poddar, M.H. Sawyer, J.D. Connor, Effect of inhibitors in clinical specimens on Taq and Tth DNA polymerase-based PCR amplification of influenza A virus., J. Med. Microbiol. 47 (1998) 1131-5. doi:10.1099/00222615-47-12-1131.

[37] Q. Zheng, C. Bustandi, Y. Yang, K.R. Schneider, H.-G. Yuk, Comparison of enrichment broths for the recovery of healthy and heat-injured Salmonella typhimurium on raw duck wings., J. Food Prot. 76 (2013) 1963-8. doi:10.4315/0362-028X.JFP-13-041.

[38] D.D. Bang, R. Dhumpa, C. Cuong, L. Florian, J. Berganzo, R. Walczak, Y. Liu, M. Bu, S. Yi, J. Dzuiban, J.M. Rruano, A. Wolff, A trip from a tube to a chip applied micro and nanotechnology in biotechnology, veterinary and life sciences, in: IFMBE Proc., 2010: pp. 291-294.

[39] Y. Sun, Q.T. Linh, T.Q. Hung, W.H. Chin, A. Wolff, B. Dang Duong, A lab-on-a-chip system with integrated sample preparation and loop-mediated isothermal amplification for rapid and quantitative detection of Salmonella spp. in food samples, Lab Chip. 15 (2015) 1898-1904. doi:10.1039/C4LC01459F. 